\title{
Numerical Simulation and Experimental Study on Shaped Charge Warhead of Guided Ammunition
}

\author{
Guangsong Ma $(i)$ and Guanglin $\mathrm{He}$ if \\ Science and Technology on Electromechanical Dynamic Control Laboratory, Beijing Institute of Technology, Beijing 10081, China \\ Correspondence should be addressed to Guanglin He; heguanglin@bit.edu.cn
}

Received 13 November 2020; Revised 4 March 2021; Accepted 1 May 2021; Published 13 May 2021

Academic Editor: Fabio Minghini

Copyright (c) 2021 Guangsong Ma and Guanglin He. This is an open access article distributed under the Creative Commons Attribution License, which permits unrestricted use, distribution, and reproduction in any medium, provided the original work is properly cited.

\begin{abstract}
To study the jet penetration capability of shaped charge warhead of guided ammunition, a variable cone angle-shaped charge liner was designed. LS-DYNA software is used to simulate the penetration capability of shaped charge warhead with three different metal materials (copper, steel, and aluminum). Numerical simulation results show that the velocity of the shaped charge jet formed by the three kinds of materials is $v_{\text {aluminum }}>v_{\text {copper }}>v_{\text {steel, }}$ and the residual velocity after penetration is $V_{\text {steel }}>V_{\text {aluminum }}>V_{\text {copper }}$, the time when the jet starts to break is $t_{\text {copper }}>t_{\text {steel }}>t_{\text {aluminum }}$, and the penetration completion time is $T_{\text {copper }}<T_{\text {aluminum }}<T_{\text {steel }}$; therefore, according to the numerical simulation results, copper was selected as the liner material, and the principle prototype is made for the experiment. The results of numerical simulation and experiment show that the shaped charge warhead with copper shaped charge liner has good penetration ability and after-effect damage ability to steel target after penetrating the guidance section, steering gear section, and control section.
\end{abstract}

\section{Introduction}

Since the discovery of the shaped charge effect of explosives in the 19th century, the shaped charge warhead with a shaped charge has been widely used due to its excellent penetration ability. The shaped charge has been developed; three types of shaped charge have been developed: jetting projectile charge (JPC), explosively formed projectile (EFP), and shaped charge jet (SCJ) [1-3]. To better understand the formation mechanism and penetration mechanism of SCJs, Rosenberg et al. [4] studied the formation and penetration mechanism of shaped charge projectile, long rod projectile, and shaped charge jet by combining experimental observation with numerical simulation and engineering model. Bai et al. [5] have studied the penetration of steel targets with pure tungsten, $\mathrm{W}-\mathrm{Ni}-\mathrm{Fe}$ alloy, and $\mathrm{W}-\mathrm{Cu}$ alloy charge and found that the interaction between jet and target is an important factor affecting the penetration performance of jet. In the process of jet formation, when the SCJs extend to a certain extent, the fracture phenomenon will occur. Ren et al. [6] studied the fracture of the jet by combining theoretical analysis and experiment. The study found that the formation of the jet is broken, there is a central hole in the metal block, and there are fluctuations during the formation of the central hole, which may be one of the reasons that cause the jet to break. However, the penetration performance of the SCJs can be controlled by external interference. For example, the penetration performance of SCJs can be improved or reduced by the control of the electromagnetic field on SCJs [7]. Shvetsov et al. [8] analyzed the effect of electromagnetic fields on the penetration of SCJs by theoretical analysis. The results show that the penetration effect of the SCJs is weakened under the action of the electromagnetic field. Ma et al. $[9,10]$ studied the influence of a strong external magnetic field on the penetration of the target by a combination of the depth of penetration (DOP) test and X-ray; the results showed that the stability and penetration depth of the SCJs are better than those of natural conditions under the influence of the external strong magnetic field. Ma et al. [11] studied the acceleration effect of 
the electromagnetic field on the SCJs through theoretical analysis and experimental verification; the research results showed that the electromagnetic field can increase the axial velocity of the SCJs. In addition to improving or reducing the penetration depth of SCJs by changing the external interference conditions, the main factors affecting the penetration depth of the SCJs are the blast height, the cone angle of the liner, the material of the liner, the performance of the explosive, and the presence or absence of separator. Dehestani et al. [12] studied the influence of explosive height and thickness of the liner on penetration performance through numerical simulation and experimental verification. Li et al. [13] studied the penetration ability of the SCJs by a ring-shaped multipoint synchronous detonation through a combination of theoretical calculations, numerical simulations, and experiments and found that multipoint synchronous initiation can improve the penetration ability of jet and improve the utilization rate of the shaped charge. $\mathrm{Xu}$ et al. [3] proposed a bore-center annular shaped charge (BCASC) and studied the penetration ability of the SCJs through experiments and numerical simulations; the results showed that the maximum wall thickness has a great influence on the penetration diameter and penetration depth of BCASC. The target plate also has a great influence on the penetration performance of shaped charge. Xiao et al. [14] analyzed the penetration ability of the SCJs on concrete with different strengths through theoretical analysis and experimental verification; the results showed that with the increase of concrete strength, the projectile diameter of the SCJs penetrating concrete decreases, and it is difficult for low-velocity jet particles to reach the bottom of the crater, which leads to the decrease of penetration depth of shaped charge jet. Besides, the penetration ability of the SCJs is affected by the interaction between jet particles and ultrahigh-strength concrete. Zhu et al. [15] studied the penetration of high-strength and ultrahigh-strength concrete by the SCJs through a combination of theoretical analysis and experiments and proposed four penetration stages; the jet may experience different penetration stages when it penetrates high or ultrahigh concrete targets, which will affect the penetration result of the SCJs. Elshenawy et al. [16] studied the penetration ability of the SCJs to Rolled Homogeneous Armor (RHA) through experiment and numerical simulation; the results showed that the penetration depth of the SCJs into the RHA target is greatly reduced with the increase of yield strength of target plate. The method of theoretical analysis and experimental verification was used by Jia et al. [17], who studied the disturbing effect of the SCJs when penetrating composite armor, and the results showed that the axial velocity, disturbance area, and lateral force have a great influence on the jet deformation. Xu et al. [18] conducted experiments and numerical simulations to study the jet formation and penetration capabilities of the ultrahigh velocity formed charge of five different material discs covering the truncated cone-shaped charge-shaped cover; the results showed that the length and head velocity of jet formed by an ultrahigh velocity forming charge with tungsten disk is larger than those of other materials. Guo et al. [19] have studied the penetration performance of the reactive liner to the target through experiments and numerical simulations; the study found that the reactive liner can penetrate a thicker steel plate, resulting in a larger aperture; however, the penetration depth is very small, and the reaction delay time of the reactive liner is the main factor for the penetration depth [19]. In the traditional shaped charge, adding waveshaper can improve the penetration ability of shaped charge, different from the traditional shaped charge; the influence of the waveshaper on the penetration ability of the reactive liner was studied in reference [20]. The research results showed that the waveshaper has a negative impact on the penetration ability of the reactive liner; the waveshaper shortens the reaction time of the reactive liner and reduces the penetration performance. Wang et al. [21] studied the penetration performance of double-layer reactive liner by numerical simulation and experiment, and the results showed that the double-layer reactive liner can enhance the penetration depth of the shaped charge jet. With the development of shaped charge warhead technology, armor protection technology is also developing, and reaction armor is used to deal with a shaped charge warhead. To enable the SCJs to effectively penetrate the armored target, the technology of tandem armorpiercing warhead has entered the field of vision of researchers. Ding et al. [22] used numerical simulation method to study the penetration of low-density material liner into reactive armor, and the results showed that the SCJs formed by low-density material liner can effectively destroy reactive armor.

According to the research in literature, researchers have studied the penetration performance of the SCJs from different aspects, including the shaping and penetration mechanism of the SCJs [4-6], the influence of electromagnetic characteristics on the penetration performance of the SCJs [7-11], the influence of target material on the penetration ability of the SCJs [3, 14-18], and the application of reactive materials in the liner [19-22]. Researchers have done a lot of research in improving or offsetting the penetration ability of the SCJs. These studies have great significance in promoting the development of the SCJs warhead technology. At present, in terms of specific engineering applications, traditional materials have certain advantages. Wang et al. [23] used the method of numerical simulation and experiment to study the penetration of the spacer target and the layered target with the three materials of copper, steel, and aluminum, and the results showed that the depth of the SCJs penetrating the spacer target and the layered target is the largest when the material is copper and the cone angle is less than $120^{\circ}$. As a part of a certainly guided munition fuse and warhead system, the designed shaped charge needs to penetrate the guidance compartment, steering gear compartment, and control compartment first and still has good penetration capability and after-effect performance against armored targets. Therefore, this study designed a variable cone angle liner, the penetration ability of the SCJs formed by three different metal liners on the target plate is numerically simulated, and their penetration ability to target plate is analyzed and compared. One of the metal liners is selected to conduct a penetration test on a layered target. 


\section{Structural Design}

2.1. Warhead Structure Design. The charge diameter of the warhead designed in this research is $100 \mathrm{~mm}$ and the charge height is $130 \mathrm{~mm}$. To improve the jet performance and improve the effect of armor-piercing, the liner adopts a variable wall thickness and variable cone angle design, the top thickness of the liner is $1.4 \mathrm{~mm}$, the thickness of the liner edge is $2 \mathrm{~mm}$, the cone angle at the top of the liner is $38^{\circ}$, and the cone angle at the edge is $60^{\circ}$. The designed warhead structure is shown in Figure 1.

2.2. Structure Equivalence of Guidance Cabin. To simulate the penetration of shaped charge jet into the simulation cabin (containing guidance cabin, steering gear cabin, and control cabin), according to the physical characteristics of various parts and materials in the simulation cabin, the cabin is equivalently treated; that is, the steering gear, motor, shell, and other metal components in the simulation cabin are equivalent to the steel plate and aluminum plate with a certain thickness; the circuit board and other parts in the simulation cabin are equivalent to a certain thickness of the plastic plate. The equivalent structure diagram is shown in Figure 2.

In the structural model of the SCJ warhead penetration simulation cabin shown in Figure 2, the simulation cabin includes the control cabin (1-5 layers), the steering gear cabin (6-18 layers), and the guidance cabin (19-25 layers); the number, name, and thickness of each layer of slices and the distance between each layer in the simulated cabin are shown in Table 1.

\section{Numerical Simulation}

3.1. Finite Element Model. At present, the mainstream grid construction software includes HyperMesh, FEMB, true grid, and ICEM [24]. The preprocessing required by the LSDYNA solver can be carried out by various means. In this study, HyperMesh is used to preprocess the designed shaped charge penetration model. The established penetration model is imported into HyperMesh for grid division; the liner grid, charge grid, and air domain grid are mainly hexahedral grids and prismatic pentahedral grids; among them, common nodes are used on the interface between the liner grid and the charge grid, common nodes are used on the interface between the liner grid and the air domain grid, common nodes are used on the interface between the charge grid and the air domain grid, and all the 26 layers target plate are hexahedral grids. Due to the large deformation of the SCJ when it penetrates the target plate, in order to avoid errors such as negative volume in the numerical simulation, the numerical simulation adopts the fluid-structure interaction algorithm; therefore, the air domain grid and the target plate grid must overlap. Since the shaped charge warhead penetration model in this study is an axisymmetric structure, to reduce the amount of calculation, the established quarter finite element model is shown in Figure 3; the number of elements is 740220 .

It can be seen from Figure 3 that the finite element model of SCJ penetrating the target plate mainly includes explosive, liner, air, simulated cabin, and steel target. Among them, the three materials of the explosive, liner, and air are modeled by Eulerian grid, the elements are based on multimaterial group algorithm, the simulation cabin and steel target are modeled by Lagrange method, and the simulation cabin, steel target, and air and liner are modeled by fluid-structure coupling algorithm.

From the finite element model shown in Figure 3, it can be seen that the order of the SCJ generated by the shaped charge to penetrate the target plate is simulation cabin (including control cabin, steering gear cabin, and guidance cabin) and steel plate; among them, the penetration model contains 26 layers of spaced targets. To study the velocity of the shaped jet after penetrating the target plate, five observation points are set to record the head velocity of the shaped jet. The set observation points are shown in Figure 4.

In Figure 4, observation point 1 represents the velocity of the SCJ before penetrating the target plate, observation point 2 represents the velocity of the SCJ after penetrating the control cabin, and observation point 3 represents the velocity of the SCJ after penetrating the steering gear cabin, observation point 4 represents the velocity after the SCJ penetrates the guidance cabin, and observation point 5 represents the velocity after the SCJ completes its penetration.

3.2. Material Constitutive Model and Parameters. In the finite element model as shown in Figure 3, 8701 explosives are selected [19, 25], high explosive material model and JWL (Jones Wilkins Lee) state equation are used, material parameters are shown in Table 2, and JWL state equation expression is shown in equation (1).

General pressure expression of the JWL equation of state is as follows [24]:

$$
p=A\left(1-\frac{\omega}{r_{1} V}\right) e^{-r_{1} V}+B\left(1-\frac{\omega}{r_{2} V}\right) e^{-r_{2} V}+\frac{\omega E}{V},
$$

where $A, B, r_{1}, r_{2}$, and $\omega$ are material constants; $V$ is the initial relative volume; $E$ is the initial specific internal energy; $\rho$ is the initial explosive density; $P_{C J}$ is the detonation pressure; $D$ is the detonation speed; $p$ is the hydrostatic pressure.

In this study, the liner materials are copper, steel, aluminum, and tungsten; the material model is JOHNSON_COOK, and the state equation is described by GRUNEISEN. The material parameters are shown in Table 3, the expression of the GRUNEISEN equation of state in compression state is shown in equation (2), and the expression in expansion state is shown in equation (3). 
Expression of GRUNEISEN equation of state in the compressed state is as follows $[26,27]$ :

$$
p=\frac{\rho_{0} C^{2} \mu\left[1+\left(1-\left(\gamma_{0} / 2\right)\right) \mu-(\alpha / 2) \mu^{2}\right]}{\left[1-\left(S_{1}-1\right) \mu-S_{2}\left(\mu^{2} /(\mu+1)\right)-S_{3}\left(\mu^{3} /(\mu+1)^{2}\right)\right]^{2}}+\left(\gamma_{0}+\alpha \mu\right) E .
$$

Expression of GRUNEISEN equation of state in expansion state is as follows:

$$
p=\rho_{0} C^{2} \mu+\left(\gamma_{0}+\alpha \mu\right) E,
$$

where $E$ is the initial internal energy; $C$ is the intercept of the $v_{s}-v_{p}$ curve; $S_{1}, S_{2}$, and $S_{3}$ are the coefficients of the slope of the $v_{s}-v_{p}$ curve; $\gamma_{0}$ is the GRUNEISEN coefficient; $\alpha$ is the first-order volume, correction of $\gamma_{0}$.

The material model in the simulation cabin adopts PLASTIC_KINEMATIC, and the material parameters are shown in Table 4.

\subsection{Numerical Simulation Result and Analysis. When the} liner material is copper, the penetration results of the SCJ are shown in Figure 5.

It can be seen from Figure 5(a), when the liner material is copper, the SCJ starts to penetrate the control cabin in the simulation cabin at about $26 \mu \mathrm{s}$. At this time, the shape of the SCJ is complete, there is no shrinkage or fracture, and the head velocity of the SCJ reaches the maximum value; that is, the head velocity is $8248 \mathrm{~m} / \mathrm{s}$; in Figure 5(b), the penetration into the control cabin is completed at about $35 \mu \mathrm{s}$. At this time, the shape of the SCJ is still complete, and there is no shrinkage or fracture; due to the interaction between the SCJ particles and the target plate, the head speed of the SCJ decreases, the head speed of the SCJ is $6302 \mathrm{~m} / \mathrm{s}$; in Figure 5(c), the penetration of the steering gear cabin is completed at about $113 \mu \mathrm{s}$. With the extension of the length of the SCJ, the difference in velocity between the head and tail of the SCJ becomes larger and larger; at this time, the SCJ begins to shrink and fracture. At the same time, due to the interaction between the particles of the SCJ and the target plate, the head speed of the SCJ continues to decrease, and the head speed of the SCJ is $5039 \mathrm{~m} / \mathrm{s}$; in Figure 5(d), the penetration of the guidance cabin is completed at $165 \mu \mathrm{s}$. At this time, the SCJ can be seen to be fracture obviously; so far, the SCJ has completed the penetration of the whole simulation cabin, and the head velocity of the SCJ is $4240 \mathrm{~m} / \mathrm{s}$; in Figure 5(e), the SCJ started to penetrate the $25 \mathrm{~mm}$ steel plate, and the penetration of the $25 \mathrm{~mm}$ steel target is completed at about $182 \mu \mathrm{s}$. Due to the unstable movement of the fracture SCJ in the air, the particles of the SCJ overturn, resulting in an irregular hole on the $25 \mathrm{~mm}$ steel plate when the jet penetrates the $25 \mathrm{~mm}$ steel plate, and the velocity of the SCJ is $3184 \mathrm{~m} / \mathrm{s}$. It can be seen that the total penetration time is $182 \mu \mathrm{s}$, which is $T_{\text {Cooper }}=182 \mu \mathrm{s}$. The velocity curve of the SCJ in the whole penetration process is shown in Figure 6.
According to Figure 6, the velocity of the SCJ at observation point 1 is $8248 \mathrm{~m} / \mathrm{s}$, that at observation point 2 is $6302 \mathrm{~m} / \mathrm{s}$, that at observation point 3 is $5039 \mathrm{~m} / \mathrm{s}$, that at observation point 4 is $4240 \mathrm{~m} / \mathrm{s}$, and that at observation point 5 is $3184 \mathrm{~m} / \mathrm{s}$. From the beginning of the SCJ penetrating the simulation cabin to the completion of the penetration of the $25 \mathrm{~mm}$ Q235 steel target, the velocity of the SCJ decreased from $8248 \mathrm{~m} / \mathrm{s}$ to $3184 \mathrm{~m} / \mathrm{s}$, which decreased by $61.4 \%$.

When the liner material is steel, the penetration results of the SCJ are shown in Figure 7.

It can be seen from Figure 7(a), when the liner material is steel, the SCJ starts to penetrate the control cabin in the simulation cabin at about $24.8 \mu \mathrm{s}$. At this time, the shape of the SCJ is complete, and there is no shrinkage or fracture, the head velocity of the SCJ reaches the maximum value; that is, the head velocity is $7867 \mathrm{~m} / \mathrm{s}$ and, in Figure $7(\mathrm{~b})$, the penetration of the control cabin is completed at about $40 \mu \mathrm{s}$. At this time, the shape of the SCJ is still complete, and there is no shrinkage or fracture; due to the interaction between the SCJ particles and the target plate, the head speed of the SCJ decreases and the head speed of the SCJ is $6505 \mathrm{~m} / \mathrm{s}$ and, in Figure $7(\mathrm{c})$, the penetration of the steering gear cabin is completed at about $118 \mu \mathrm{s}$. With the extension of the length of the SCJ, the difference in velocity between the head and tail of the SCJ becomes larger and larger; at this time, the SCJ begins to shrink and fracture. At the same time, due to the interaction between the particles of the SCJ and the target plate, the head speed of the SCJ continues to decrease, and the head speed of the SCJ is $4922 \mathrm{~m} / \mathrm{s}$ and, in Figure $7(\mathrm{~d})$, the penetration of the guidance cabin is completed at about $174 \mu \mathrm{s}$. At this time, the SCJ can be seen to be fracture obviously; so far, the SCJ has completed the penetration of the whole simulation cabin, and the head velocity of the SCJ is $4435 \mathrm{~m} / \mathrm{s}$. In Figure 7(e), the SCJ started to penetrate the $25 \mathrm{~mm}$ steel plate, and the penetration of the $25 \mathrm{~mm}$ steel target is completed at about $192 \mu \mathrm{s}$; due to the unstable movement of the fracture SCJ in the air, the particles of the SCJ overturn, resulting in an irregular hole on the $25 \mathrm{~mm}$ steel plate when the jet penetrates the $25 \mathrm{~mm}$ steel plate, and the velocity of the SCJ is $4018 \mathrm{~m} / \mathrm{s}$. It can be seen that the total penetration time is $192 \mu \mathrm{s}$, which is $T_{\text {Steel }}=192 \mu \mathrm{s}$. The velocity curve of the SCJ in the whole penetration process is shown in Figure 8.

According to Figure 8, the velocity of the SCJ at observation point 1 is $7867 \mathrm{~m} / \mathrm{s}$, that at observation point 2 is $6505 \mathrm{~m} / \mathrm{s}$, that at observation point 3 is $4922 \mathrm{~m} / \mathrm{s}$, that at observation point 4 is $4435 \mathrm{~m} / \mathrm{s}$, and that at observation point 5 is $4018 \mathrm{~m} / \mathrm{s}$. From the beginning of the SCJ 


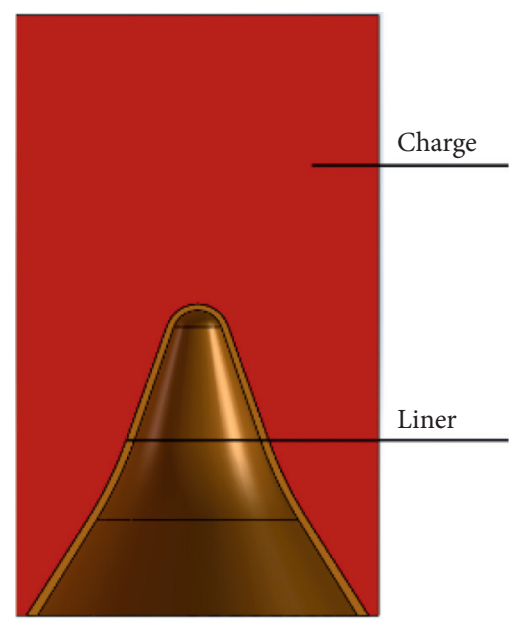

FIgURE 1: Warhead structure.

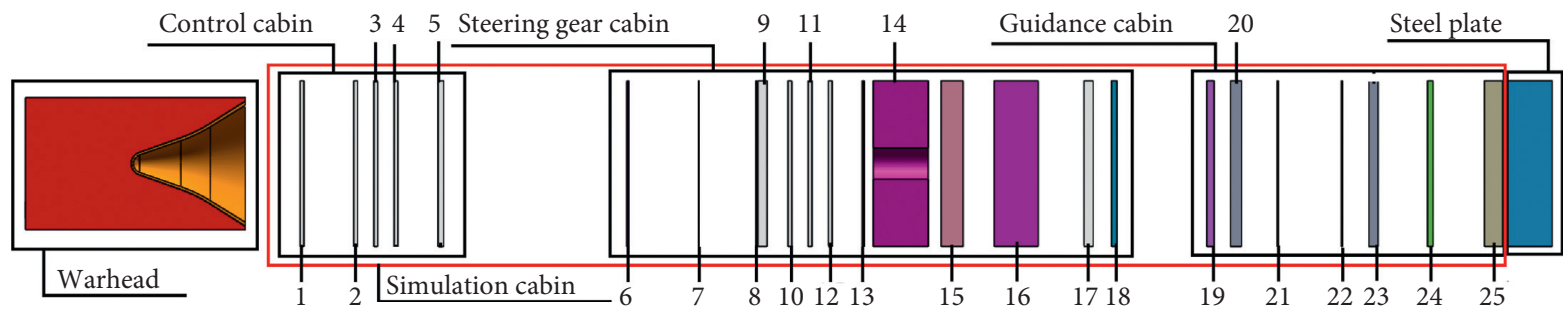

FIgURE 2: Equivalence principle model.

TABle 1: Parameters of each layer slices.

\begin{tabular}{|c|c|c|c|c|c|}
\hline & & Layer & Name & Thickness (mm) & $\begin{array}{l}\text { Distance to the } \\
\text { upper layer }(\mathrm{mm})\end{array}$ \\
\hline & & 1 & Control cabin shell & 2 & 0 \\
\hline & & 2 & Circuit board 1 & 2 & 27.3 \\
\hline & Control cabin & 3 & Circuit board 2 & 2 & 9 \\
\hline & & 4 & Circuit board 3 & 2 & 9 \\
\hline & & 5 & Control cabin shell & 3 & 22 \\
\hline & & 6 & Power connector & 1 & 100 \\
\hline & & 7 & Analog power 1 & 0.5 & 38 \\
\hline & & 8 & Analog power 2 & 0.5 & 31 \\
\hline & & 9 & Steering gear cabin shell & 5 & 0.5 \\
\hline & & 10 & Circuit board 1 & 2 & 11.5 \\
\hline & & 11 & Circuit board 2 & 2 & 9 \\
\hline & Steering gear cabin & 12 & Circuit board 3 & 2 & 9 \\
\hline Simulation cabin & & 13 & Steering gear cabin shell & 1 & 16.5 \\
\hline & & 14 & Steering gear shaft 1 & 30 & 5 \\
\hline & & 15 & Steering gear shaft 2 & 12 & 7 \\
\hline & & 16 & Electrical machinery & 24 & 17 \\
\hline & & 17 & Circuit board 4 & 5 & 25 \\
\hline & & 18 & Power connector bracket & 3 & 10 \\
\hline & & 19 & Guidance cabin shell & 4 & 49 \\
\hline & & 20 & Circuit board & 6 & 9 \\
\hline & & 21 & Analog power 1 & 0.5 & 19.5 \\
\hline & Guidance cabin & 22 & Analog power 2 & 0.5 & 34.5 \\
\hline & & 23 & Analog gyroscope sensor & 5 & 14.5 \\
\hline & & 24 & Guidance cabin shell & 3 & 27 \\
\hline & & 25 & Glass hood & 10 & 28 \\
\hline & plate & & Steel plate & 25 & 2 \\
\hline
\end{tabular}




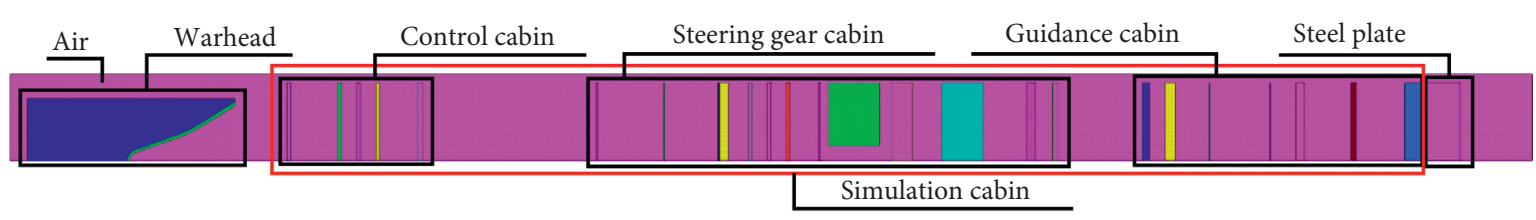

FIGURE 3: Finite element model.

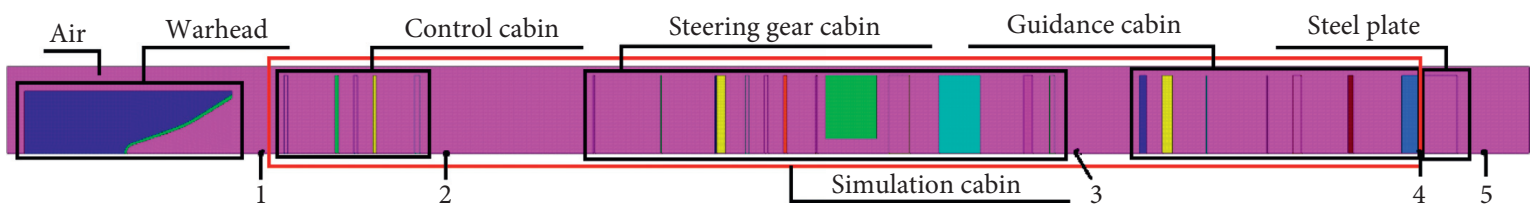

FIgURE 4: Schematic diagram of the observation point.

TABle 2: Material parameters for 8701 explosives.

\begin{tabular}{lcccccccccc}
\hline Material & $\rho\left(\mathrm{g} / \mathrm{cm}^{3}\right)$ & $D(\mathrm{~cm} / \mu \mathrm{s}))$ & $P_{C J}(\mathrm{GPa})$ & $E(\mathrm{GPa})$ & $A(\mathrm{GPa})$ & $B(\mathrm{GPa})$ & $r_{1}$ & $r_{2}$ & $\omega$ & $v_{0}$ \\
\hline Explosive & 1.71 & 0.83 & 28.6 & 8.5 & 524.23 & 7.678 & 34 & 1.1 & 0.34 & 1 \\
\hline
\end{tabular}

TABLE 3: Material parameters for liner.

\begin{tabular}{lcccccccccccc}
\hline Material & $\rho\left(\mathrm{g} / \mathrm{cm}^{3}\right)$ & $G(\mathrm{GPa})$ & $A(\mathrm{MPa})$ & $B(\mathrm{MPa})$ & $n$ & $C$ & $m$ & $T_{m}(\mathrm{~K})$ & $T_{\text {room }}(\mathrm{K})$ & $c_{0}(\mathrm{~cm} / \mu \mathrm{s})$ & $S$ \\
\hline Copper & 8.93 & 46.5 & 90 & 292 & 0.31 & 0.025 & 1.09 & 1356 & 293 & 0.39 & 1.49 \\
Steel & 7.8 & 79 & 813 & 601 & 0.28 & 0.0139 & 1.04 & 1723 & 293 & 0.46 & 1.33 \\
Aluminum & 2.7 & 26 & 369 & 684 & 0.73 & 0.0083 & 1.7 & 1356 & 293 & 0.54 & 1.34 \\
\hline
\end{tabular}

TABLE 4: Material parameters for simulation cabin.

\begin{tabular}{lcccc}
\hline Material & $\rho\left(\mathrm{g} / \mathrm{cm}^{3}\right)$ & $E(\mathrm{GPa})$ & NUXY & Yield stress $(\mathrm{MPa})$ \\
\hline Steel & 7.8 & 207 & 0.3 & 355 \\
Aluminum & 2.7 & 71 & 0.33 & 90 \\
Printed circuit board material & 1.19 & 7.8 & - & - \\
\hline
\end{tabular}

penetrating the simulation cabin to the completion of the penetration of the $25 \mathrm{~mm}$ Q235 steel target, the velocity of the SCJ decreased from $7867 \mathrm{~m} / \mathrm{s}$ to $4018 \mathrm{~m} / \mathrm{s}$, which decreased by $61.4 \%$.

When the liner material is aluminum, the penetration results of the SCJ are shown in Figure 9.

It can be seen from Figure 9(a), when the liner material is aluminum, the SCJ starts to penetrate the control cabin in the simulation cabin at about $20.8 \mu \mathrm{s}$. At this time, the shape of the SCJ is complete, and there is no shrinkage or fracture, and the head velocity of the SCJ reaches the maximum value; that is, the head velocity is $9753 \mathrm{~m} / \mathrm{s}$. In Figure 9(b), the penetration of the control cabin is completed at about $35 \mu \mathrm{s}$; at this time, the shape of the SCJ is still complete, and there is no shrinkage or fracture. Due to the interaction between the SCJ particles and the target plate, the head speed of the SCJ decreases, and the head speed of the SCJ is $8027 \mathrm{~m} / \mathrm{s}$. In Figure 9(c), penetration of the steering gear cabin is completed at about $112 \mu \mathrm{s}$; with the extension of the length of the SCJ, the difference in velocity between the head and tail of the SCJ becomes larger and larger. At this time, the SCJ begins to shrink and fracture; at the same time, due to the interaction between the particles of the shaped jet and the target plate, the head speed of the SCJ continues to decrease and the head speed of the SCJ is $5217 \mathrm{~m} / \mathrm{s}$. In Figure 9(d), the penetration of the guidance cabin is completed at about $168 \mu \mathrm{s}$. At this time, the SCJ can be seen to be fracture obviously; so far, the SCJ has completed the penetration of the whole simulation cabin, and the head velocity of the SCJ is $4616 \mathrm{~m} / \mathrm{s}$. In Figure 9(e), the SCJ started to penetrate the $25 \mathrm{~mm}$ steel plate, and the penetration of the $25 \mathrm{~mm}$ steel target is completed at about $190 \mu \mathrm{s}$. Due to the unstable movement of the fracture SCJ in the air, the particles of the SCJ overturn, resulting in an irregular hole on the $25 \mathrm{~mm}$ steel plate when the jet penetrates the $25 \mathrm{~mm}$ steel plate, and the velocity of the SCJ is $3295 \mathrm{~m} / \mathrm{s}$. It can be seen that the total penetration time is $190 \mu \mathrm{s}$, which is $T_{\text {Aluminum }}=190 \mu \mathrm{s}$. The velocity curve of the SCJ in the whole penetration process is shown in Figure 10.

According to Figure 10, the velocity of the SCJ at observation point 1 is $9753 \mathrm{~m} / \mathrm{s}$, that at observation point 2 is $8027 \mathrm{~m} / \mathrm{s}$, that at observation point 3 is $5217 \mathrm{~m} / \mathrm{s}$, that at 


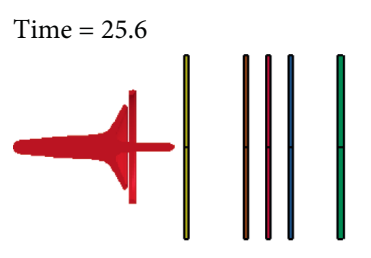

Time $=35.9$

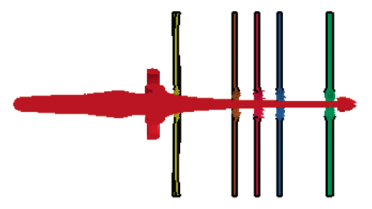

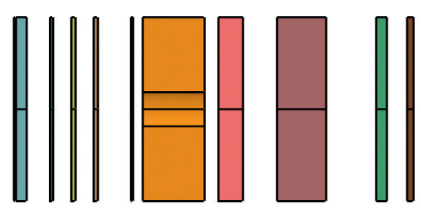

(a)
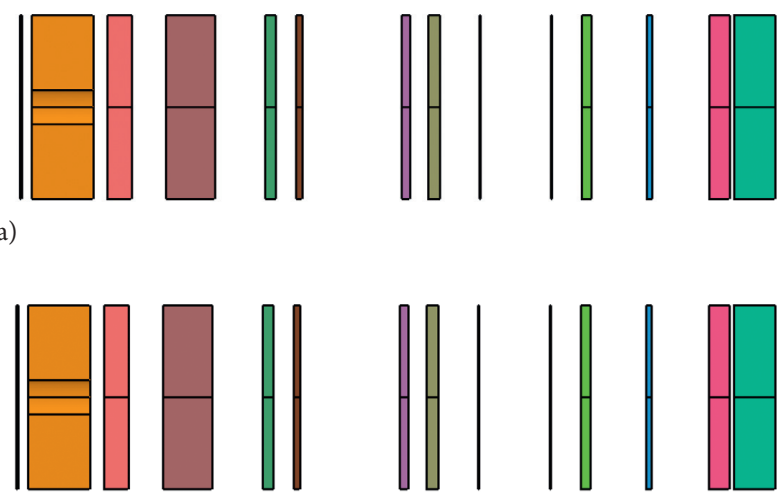

(b)

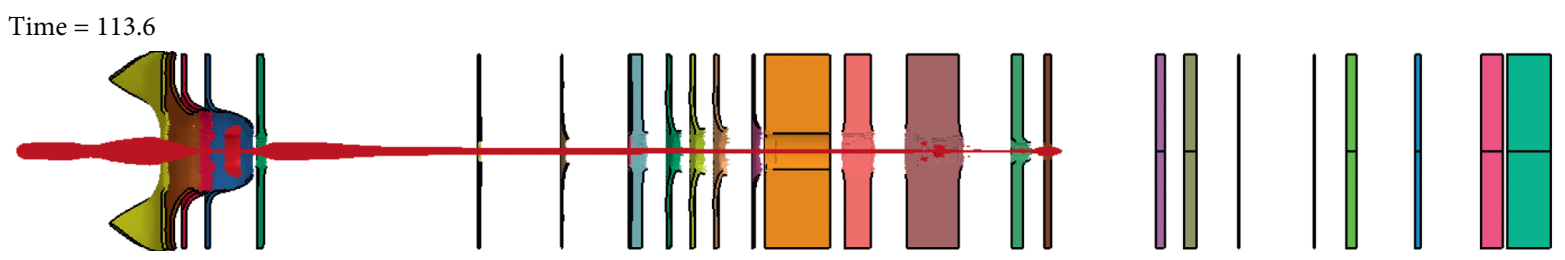

(c)

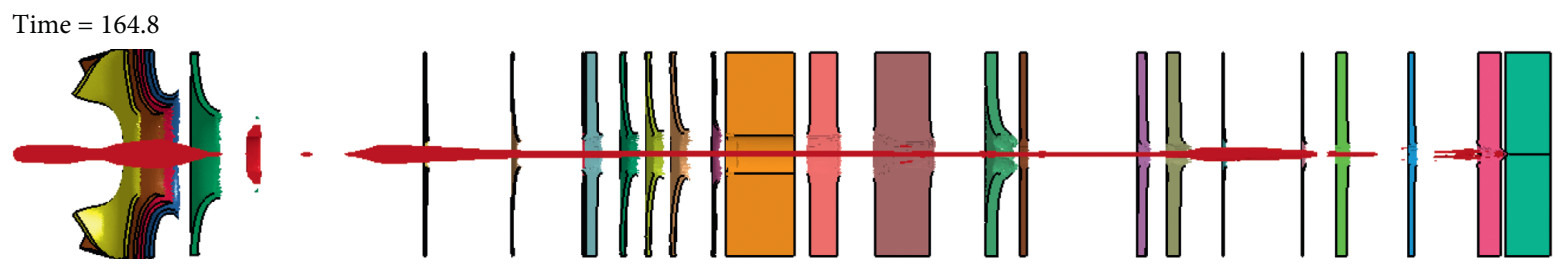

(d)

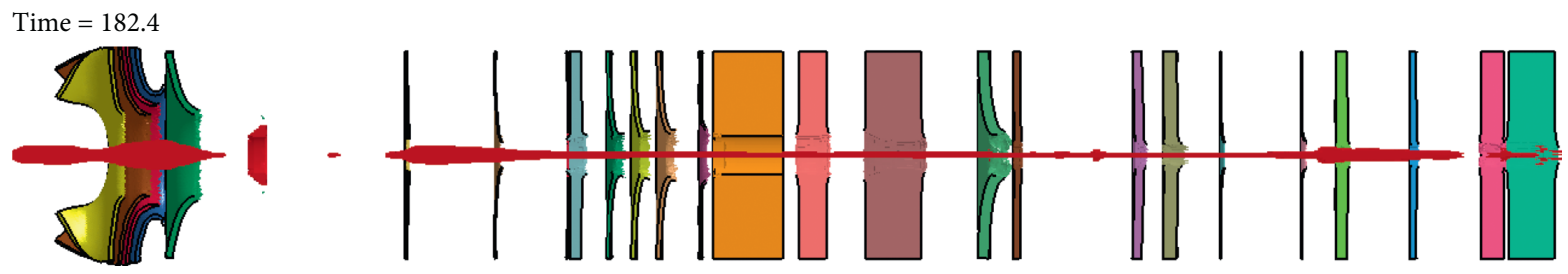

(e)

Figure 5: Penetration results of jet formed when liner material is copper: (a) the SCJ at observation point 1; (b) the SCJ at observation point 2; (c) the SCJ at observation point 3; (d) the SCJ at observation point 4; (e) the SCJ at observation point 5.

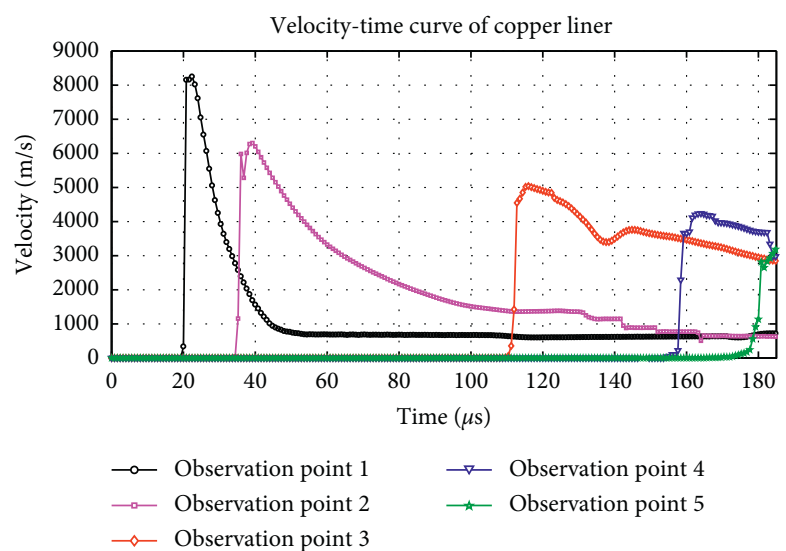

FIGURE 6: SCJ velocity curve of the copper liner. 

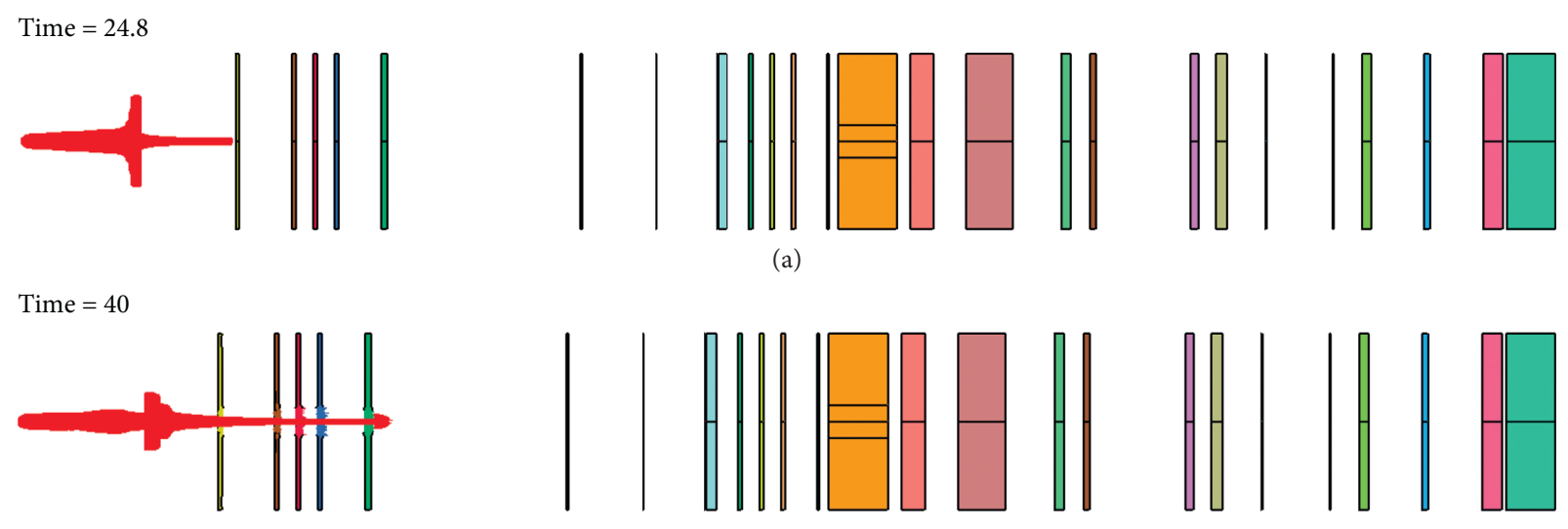

(a)
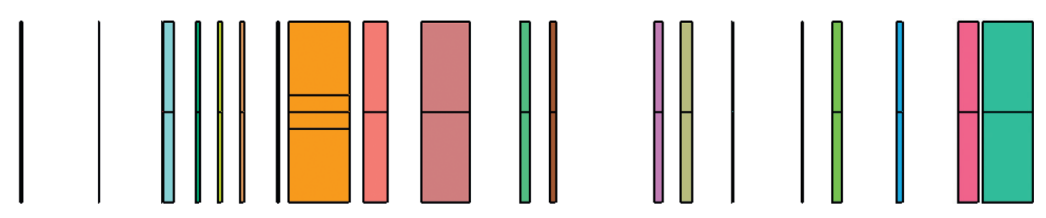

(b)
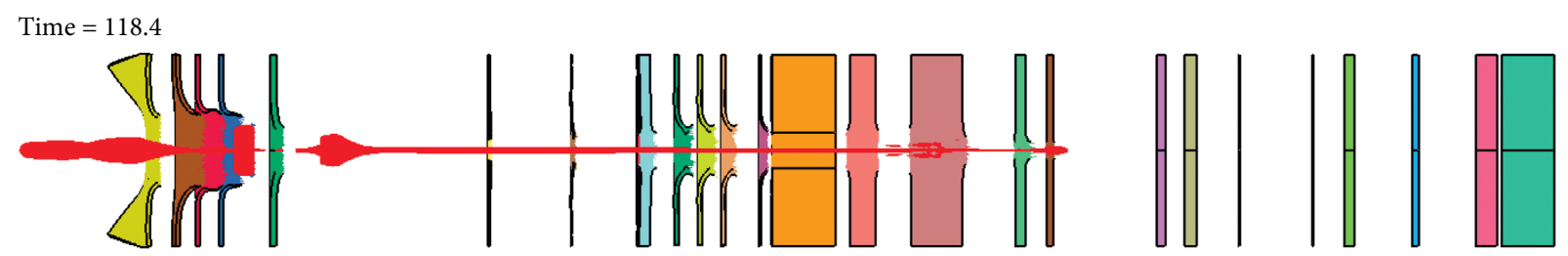

(c)

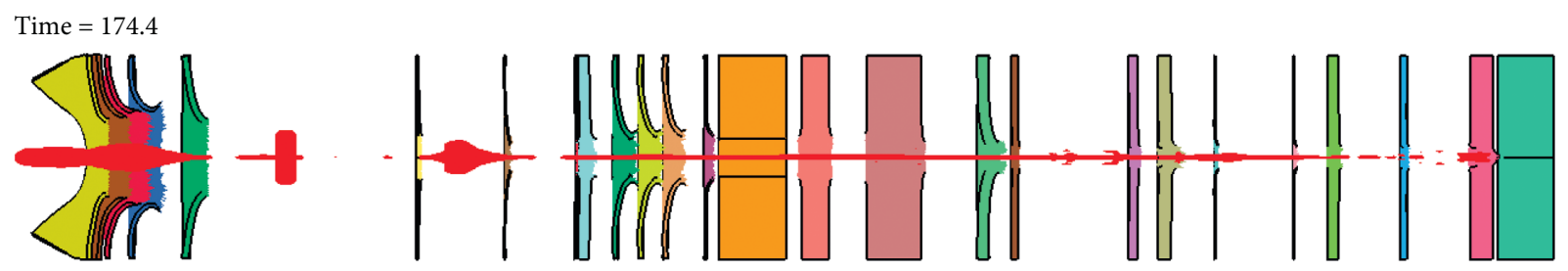

(d)
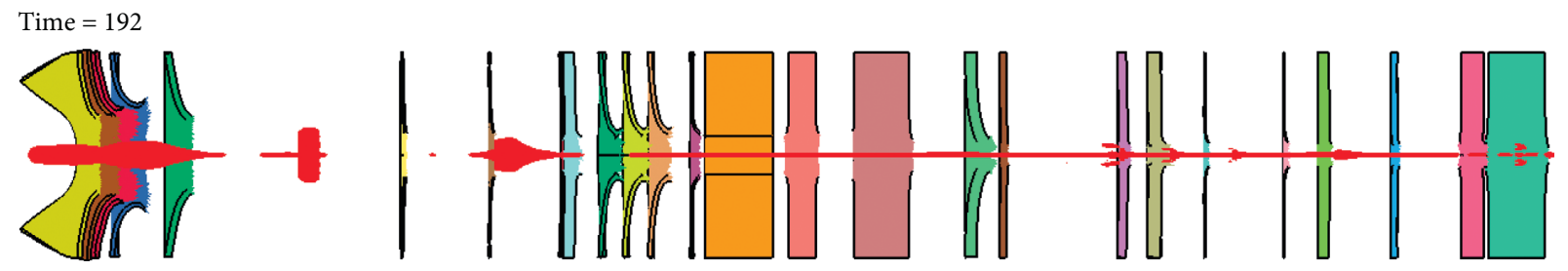

(e)

FIgURE 7: Penetration results of jet formed when liner material is steel: (a) the SCJ at observation point 1; (b) the SCJ at observation point 2; (c) the SCJ at observation point 3; (d) the SCJ at observation point 4; (e) the SCJ at observation point 5.

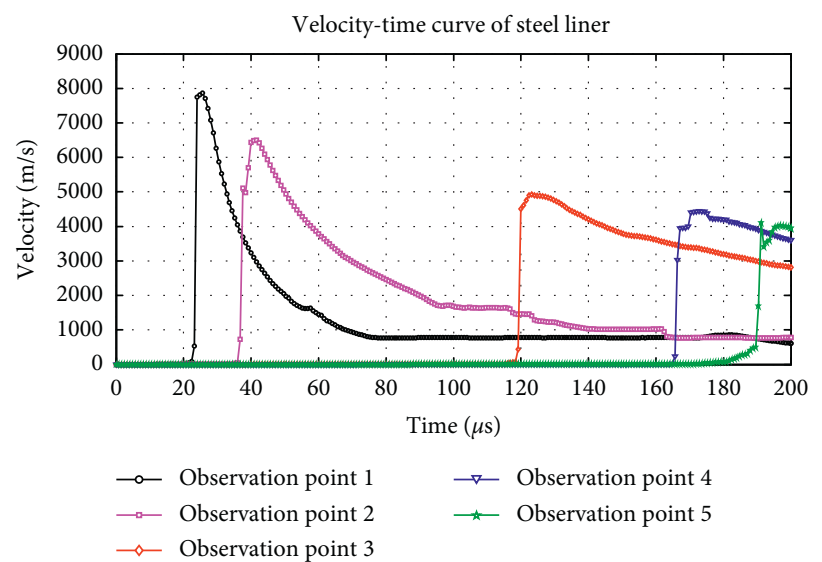

Figure 8: SCJ velocity curve of the steel liner. 


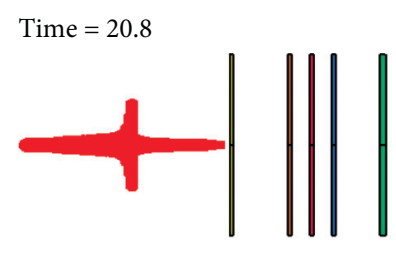

Time $=35.2$

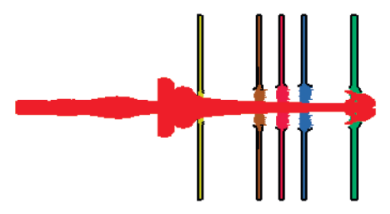

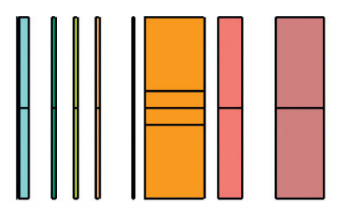

(a)
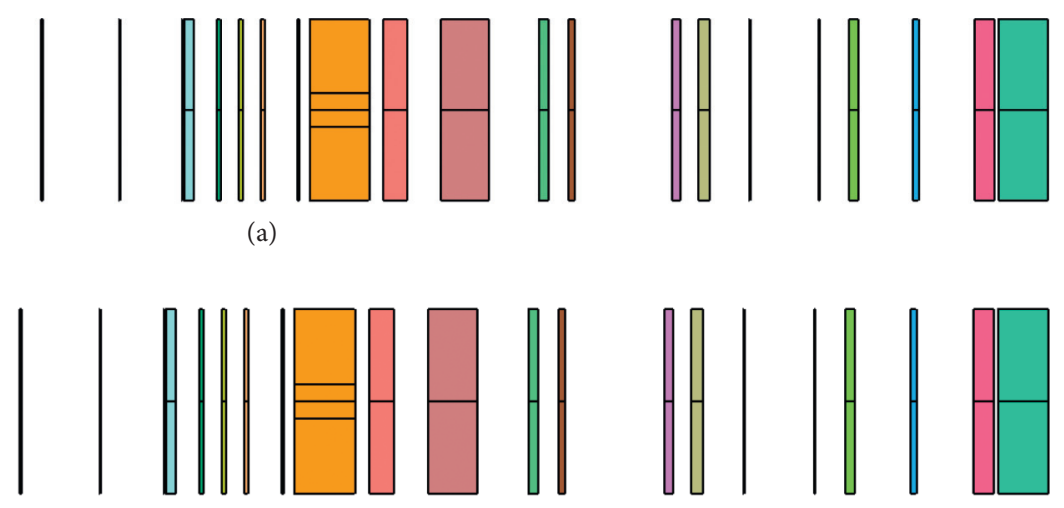

(b)
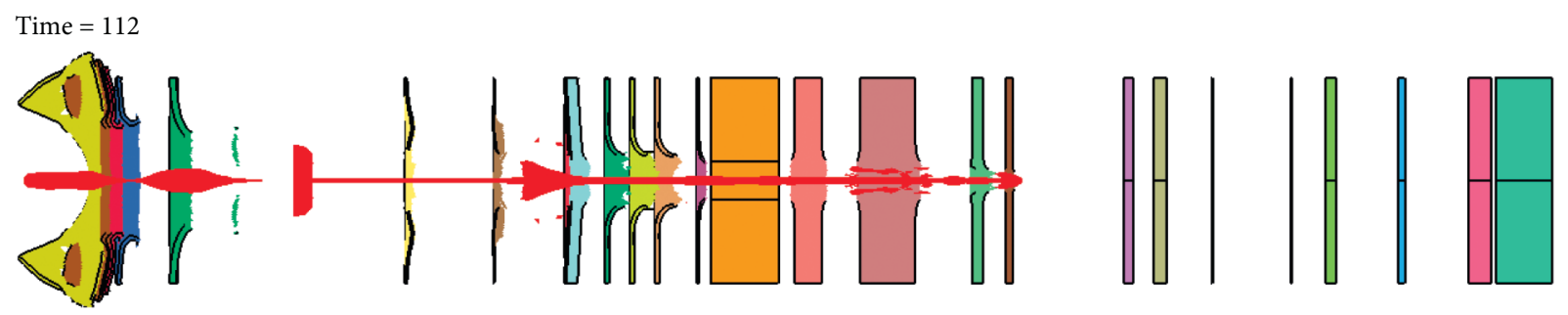

(c)
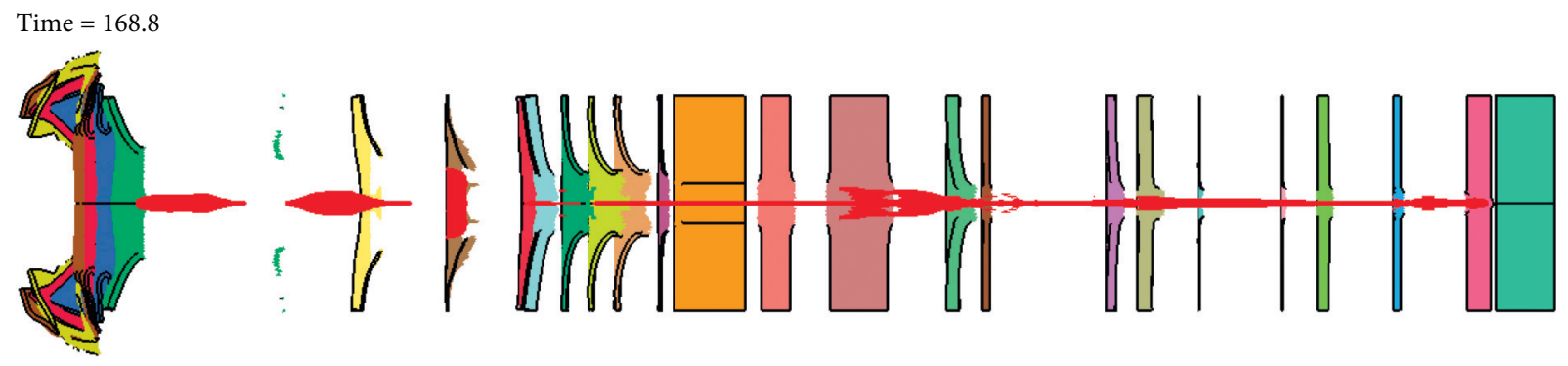

(d)
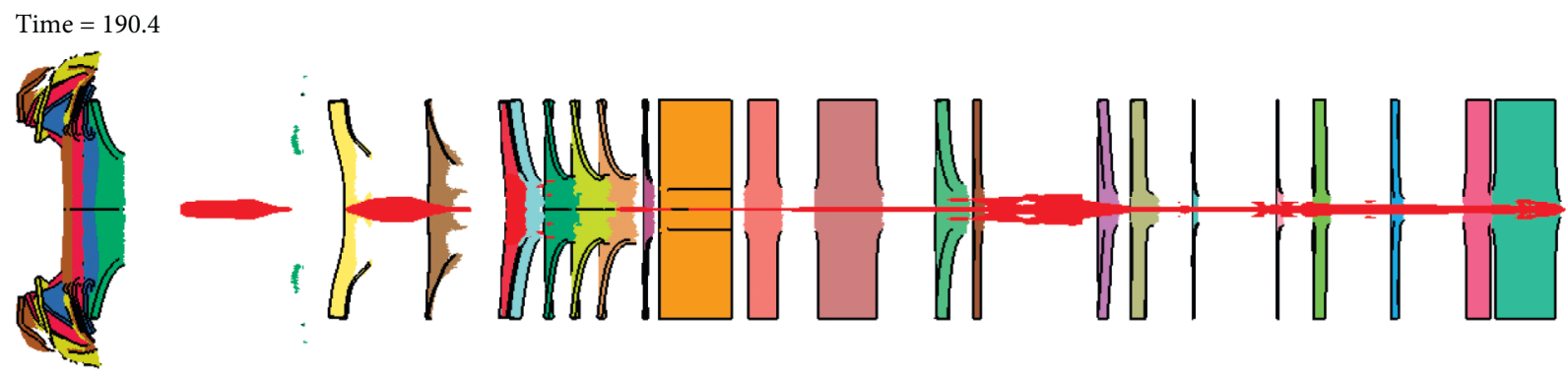

(e)

FIgURE 9: Penetration results of jet formed when liner material is aluminum: (a) the SCJ at observation point 1; (b) the SCJ at observation point 2; (c) the SCJ at observation point 3; (d) the SCJ at observation point 4; (e) the SCJ at observation point 5.

observation point 4 is $4616 \mathrm{~m} / \mathrm{s}$, and that at observation point 5 is $3295 \mathrm{~m} / \mathrm{s}$. From the beginning of the SCJ penetrating the simulation cabin to the completion of the penetration of the $25 \mathrm{~mm}$ Q235 steel target, the velocity of the SCJ decreased from $9753 \mathrm{~m} / \mathrm{s}$ to $3295 \mathrm{~m} / \mathrm{s}$, which decreased by $66.2 \%$.

Figure 11 shows the time and location of the fracture of the jets of the three different materials in the process of penetration.
It can be seen from Figure 11 that when the liner material is copper, the SCJ begins to fracture after penetrating the 17th target plate (located in the steering gear cabin). As shown in Figure 11(a), the jet fracture time is $112.8 \mu \mathrm{s}$, that is, $t_{\text {Cooper }}=112.8 \mu \mathrm{s}$. When the liner material is steel, the SCJ begins to fracture after penetrating the 15th layer target plate (located in the steering gear cabin). As shown in Figure $11(\mathrm{~b})$, the jet fracture time is $104.8 \mu \mathrm{s}$, that is, $t_{\text {Steel }}=104.8 \mu \mathrm{s}$. When the liner material is aluminum, the 


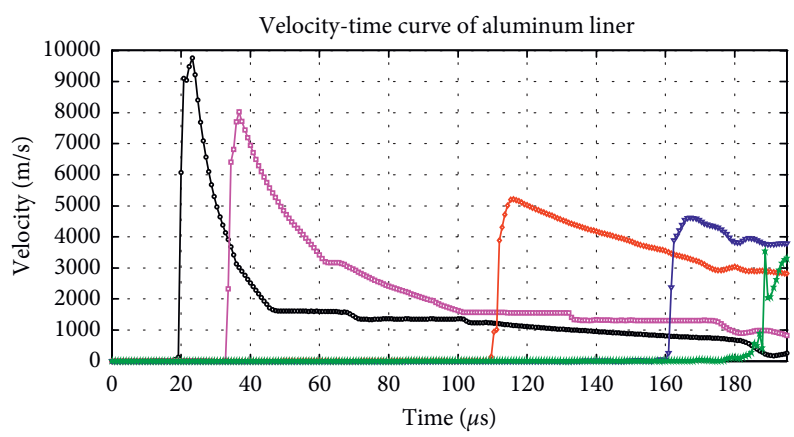

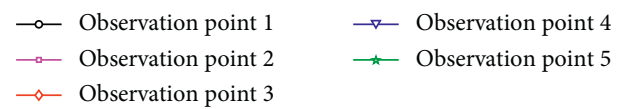

FIgURE 10: SCJ velocity curve of the aluminum liner.

SCJ begins to fracture after penetrating the 14th target plate (located in the steering gear cabin). As shown in Figure $11(\mathrm{c})$, the jet fracture time is $90 \mu \mathrm{s}$, that is, $t_{\text {Aluminum }}=90 \mu \mathrm{s}$. After the SCJ is extended to a certain extent in the air, it will shrink and fracture, the jet will fracture into small segments and it will turn over when moving in the air, which will weaken the penetration ability; that is to say, the earlier the SCJ fracture occurs, the more the penetration ability of the SCJ will be weakened. According to the numerical simulation results shown in Figure 11, when the liner material is copper, the continuous jet duration is the longest; when the liner material is aluminum, the continuous jet time is the shortest, and the density of aluminum is small, which will be vaporized in the process of jet formation, which will affect the penetration performance of the jet. Theoretically, the longer the duration of the continuous jet, the better the penetration performance. The relevant experimental results show that for the same structure of liner, the penetration depth of copper is the deepest [1]. The numerical simulation results of three kinds of liner show that the duration of the continuous jet is the longest when the liner material is copper, and the armor-breaking effect is the best among the three materials.

The velocity comparison diagram of the SCJ formed by the three different materials of the liner at the five observation points is shown in Figure 12.

It can be seen from Figure 12 that the initial velocity of the jet formed by the three different materials of the liner is $\left(v_{\text {Aluminum }}=9753 \mathrm{~m} / \mathrm{s}\right)>\left(v_{\text {Cooper }}=8248 \mathrm{~m} / \mathrm{s}\right)>\left(v_{\text {Steel }}=7867 \mathrm{~m} / \mathrm{s}\right)$. The velocity after penetration is $\left(V_{\text {Steel }}=4018 \mathrm{~m} / \mathrm{s}\right)$ $>\left(V_{\text {Aluminum }}=3295 \mathrm{~m} / \mathrm{s}\right)>\left(V_{\text {Cooper }}=3184 \mathrm{~m} / \mathrm{s}\right)$.

The results show that when the material of the liner is copper, the maximum initial velocity of the jet is $8248 \mathrm{~m} / \mathrm{s}$, the duration of the continuous jet is about $112.8 \mu \mathrm{s}$, the remaining velocity after the penetration is $3184 \mathrm{~m} / \mathrm{s}$, and the completion time of the penetration is $182.4 \mu \mathrm{s}$. When the material of the liner is steel, the maximum initial velocity of the jet is $7867 \mathrm{~m} / \mathrm{s}$, the duration of the continuous jet is about $104.5 \mu \mathrm{s}$, the remaining velocity after the penetration is $4018 \mathrm{~m} / \mathrm{s}$, and the completion time of the penetration is $192 \mu \mathrm{s}$. When the material of the liner is aluminum, the maximum initial velocity of the jet is $9753 \mathrm{~m} / \mathrm{s}$, the duration of the continuous jet is about
$90 \mu \mathrm{s}$, the remaining velocity after the penetration is $3295 \mathrm{~m} / \mathrm{s}$, and the completion time of the penetration is $190.4 \mu \mathrm{s}$. Considering the completion time of jet penetration, the duration of the continuous jet, and the time when the jet begins to break, it is reasonable to choose copper as the material of the liner of the armor-piercing warhead of a guided munition.

\section{Experimental Research}

4.1. Experimental Setup. Based on the numerical simulation results of the SCJ penetrating the target plate when the liner materials are copper, steel, and aluminum, copper is selected as the principle prototype of the liner material and the experiment is carried out. The schematic diagram of the experiment device is shown in Figure 13.

It can be seen from Figure 13 that the experimental device from top to bottom is warhead, simulation cabin, $25 \mathrm{~mm}$ Q235 steel plate, and $10 \mathrm{~mm}$ Q235 steel plate for the after-effect. According to the numerical simulation results, when the liner material is copper, the residual velocity of the SCJ is $3184 \mathrm{~m} / \mathrm{s}$ after completing the simulation cabin and $25 \mathrm{~mm}$ Q235 steel plate. To verify the penetration ability of the jet residual velocity, the Q235 steel plate with a thickness of $10 \mathrm{~mm}$ was set as the after-effect target plate. To ensure that the SCJ can penetrate the target vertically, the levelness of the experimental platform is corrected before the experiment, and the levelness of the experimental platform is adjusted by the level instrument, as shown in Figure 14.

4.2. Experimental Result and Analysis. After adjusting the levelness, the shaped charge warhead is installed on the upper part of the simulated cabin, and the warhead is detonated. A portion of the debris collected from the simulated cabin after the experiment is shown in Figure 15.

The results of the SCJ after completing the simulation cabin and $25 \mathrm{~mm}$ Q235 steel target are shown in Figure 16.

It can be seen from Figure 16 that the shape of the hole left by the shaped jet after penetrating the $25 \mathrm{~mm}$ Q235 steel target is not circular or approximately circular; this is because the shaped jet has broken before penetrating the $25 \mathrm{~mm}$ Q235 steel target and part of the jet has overturned, 
Time $=112.8$
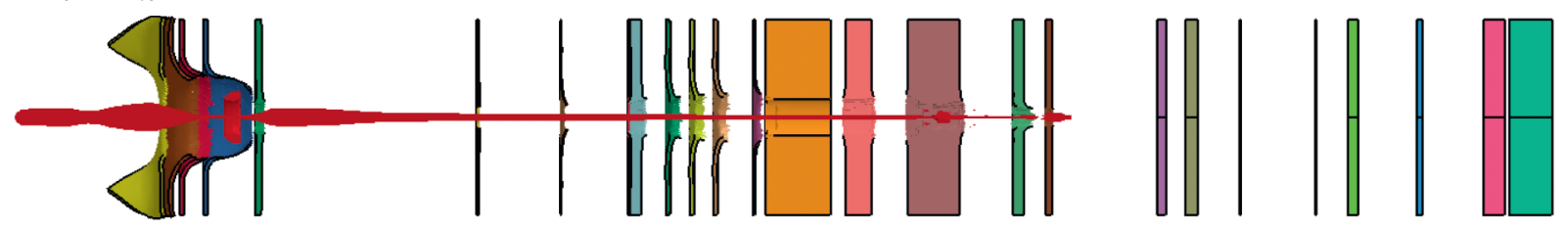

(a)
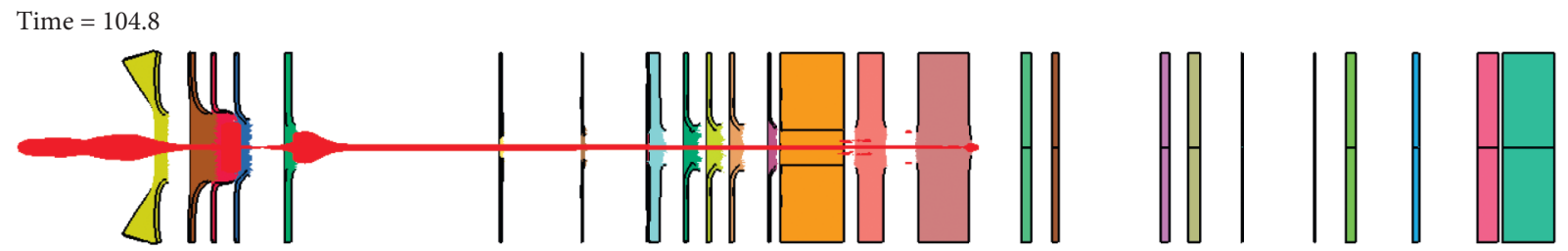

(b)
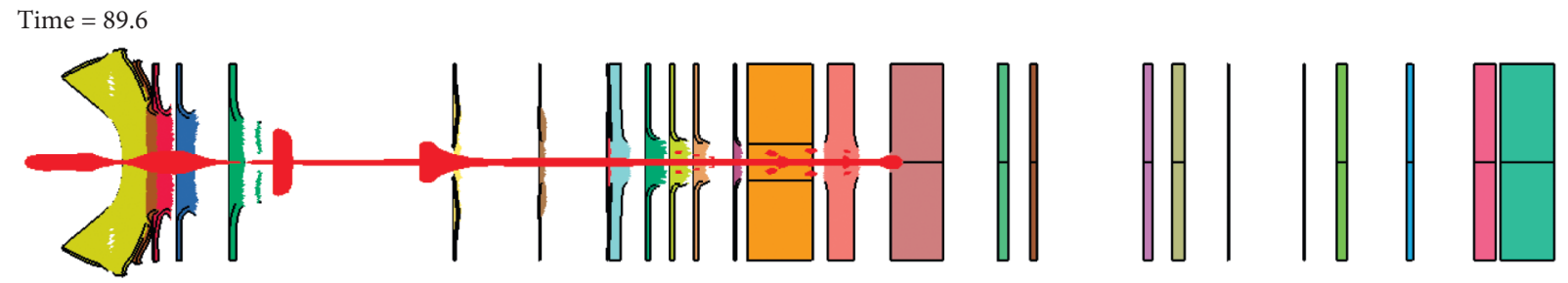

(c)

FIgURE 11: The time and position of jet fracture: (a) the liner is copper; (b) the liner is steel; (c) the liner is aluminum.

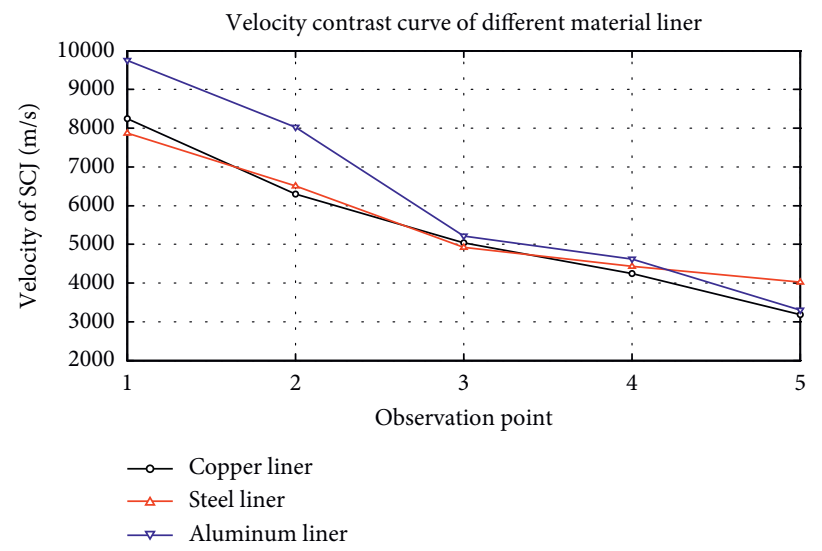

Figure 12: Velocity comparison of three kinds of material liner.

resulting in the irregular shape of the aperture after penetrating the $25 \mathrm{~mm}$ Q235 steel target.

Figure 17 shows the result of the residual jet penetration of the after-effect target after the SCJ has penetrated the $25 \mathrm{~mm}$ Q235 steel target.

It can be seen from Figure 17 that the residual jet can penetrate the $10 \mathrm{~mm}$ thick Q235 after-effect steel target, and the residual jet leaves many irregular small holes on the $10 \mathrm{~mm}$ Q235 after-effect steel target.

The experimental results show that when the liner material is copper, the shaped charge warhead can not only complete the penetration of $25 \mathrm{~mm}$ Q235 steel target but also has a good after-effect; that is, the residual jet can complete the penetration of $10 \mathrm{~mm}$ Q235 steel target. 


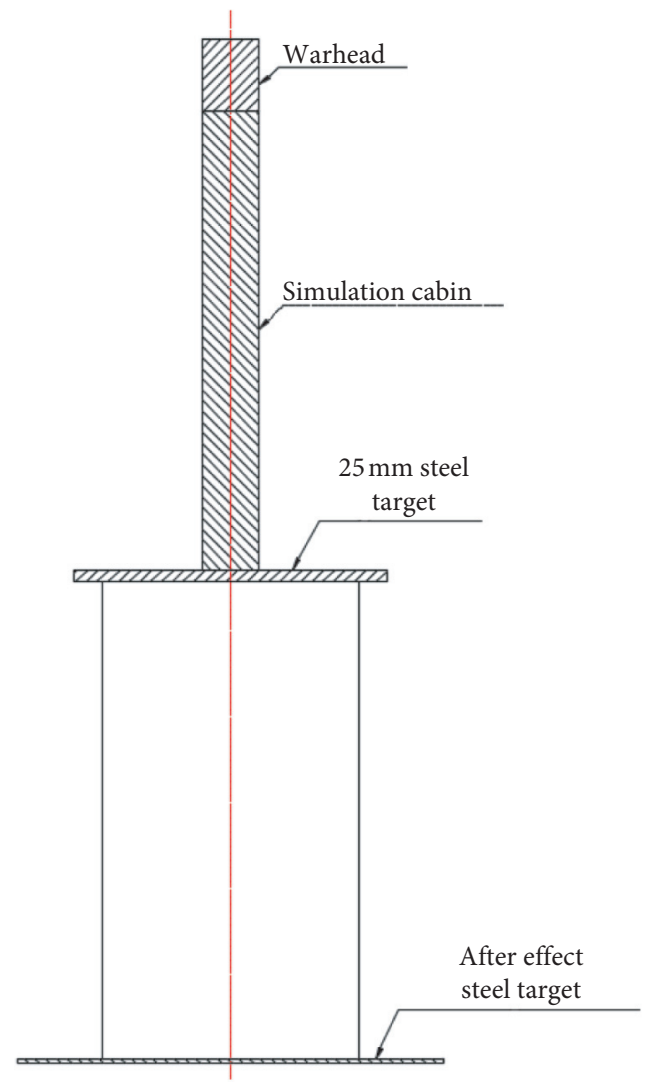

FIgURE 13: Schematic diagram of the experimental set.

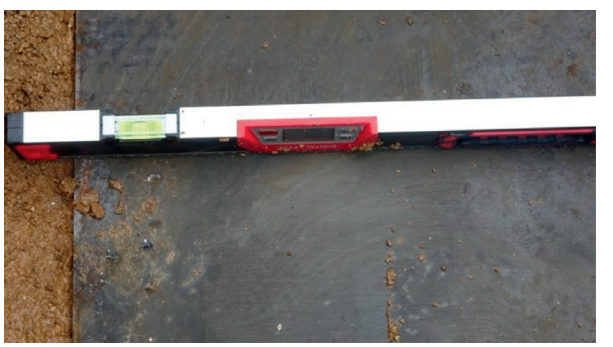

(a)

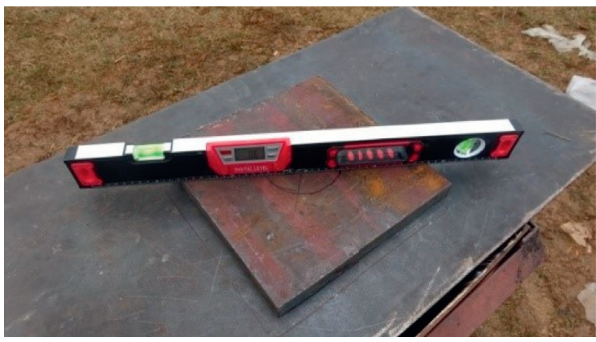

(c)

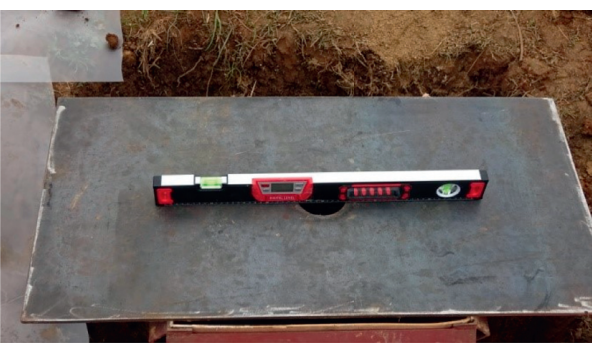

(b)

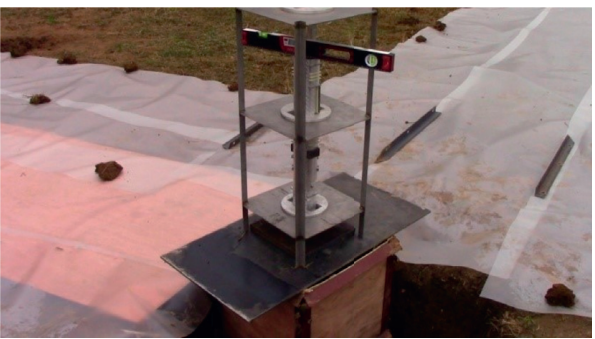

(d)

Figure 14: Level adjustment of the experimental platform: (a) level adjustment of the after-effect target plate of $10 \mathrm{~mm}$ thick Q235 steel plate; (b) level adjustment of the experimental bench; (c) levelness of the $25 \mathrm{~mm}$ thick Q235 steel target plate adjustment; (d) the levelness adjustment of the simulated cabin. 


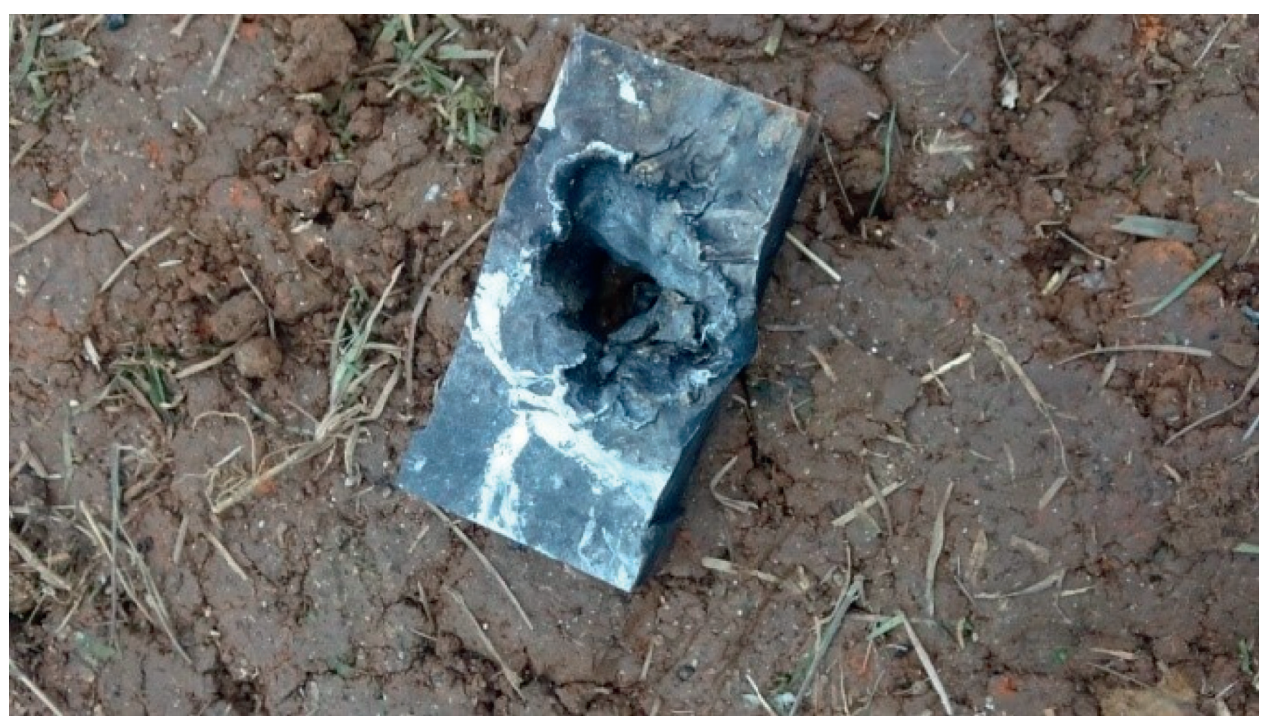

(a)

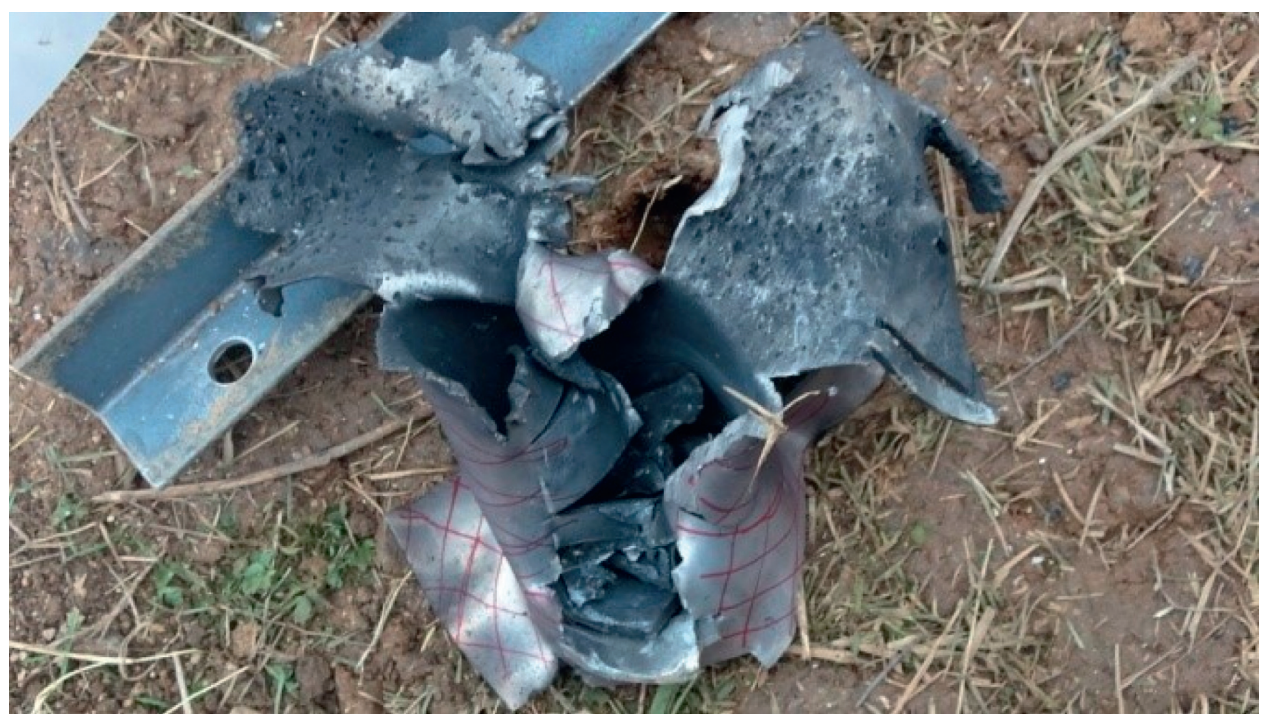

(b)

FIGURE 15: Wreckage of simulated guidance cabin.

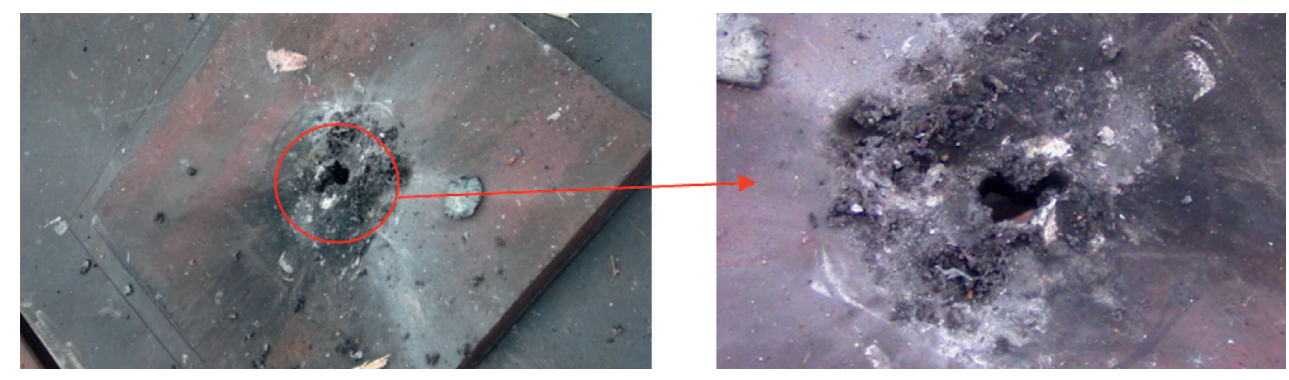

FIGURE 16: Experimental result of penetrating $25 \mathrm{~mm}$ target. 


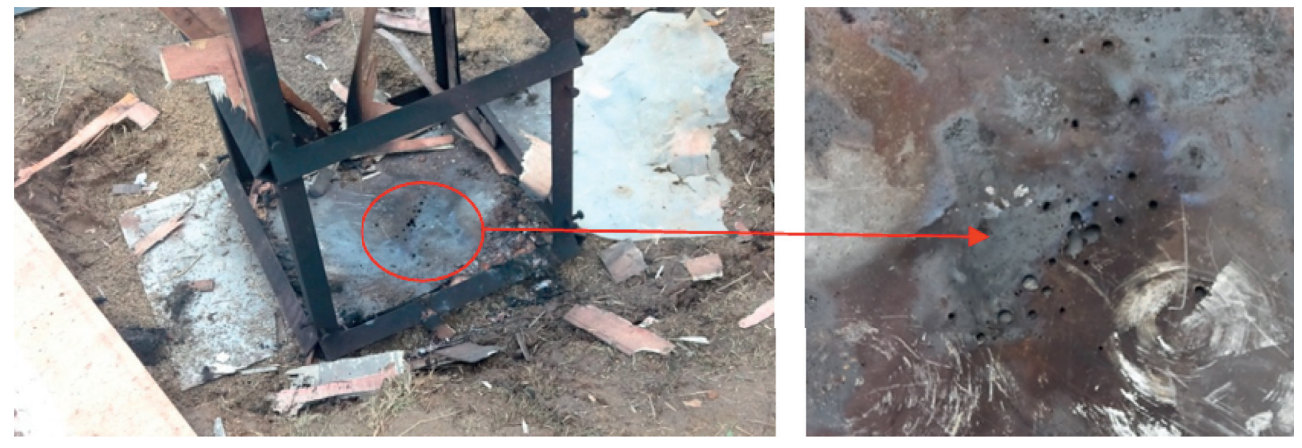

FiguRE 17: Experimental result of penetrating $10 \mathrm{~mm}$ after-effect target.

\section{Conclusion}

In this article, the penetration ability of the shaped charge warhead of the guided ammunition is studied by combining numerical simulation and experiment. In this study, the shaped charge warhead with a variable cone angle and wall thickness is designed, and the liner of different materials is simulated by LS-DYNA software. After analyzing the results of the numerical simulation, copper was selected as the material of the liner, and the principle prototype was made, and the penetration ability of the shaped charge piercing warhead was tested, and the following conclusions were drawn:

(1) The numerical simulation results show that the velocity of the SCJ formed by the three kinds of materials is $\left(v_{\text {Aluminum }}=9753 \mathrm{~m} / \mathrm{s}\right)>\left(v_{\text {Cooper }}=8248 \mathrm{~m} / \mathrm{s}\right)$ $>\left(v_{\text {Steel }}=7867 \mathrm{~m} / \mathrm{s}\right)$; the residual velocity after penetration is $\left(V_{\text {Steel }}=4018 \mathrm{~m} / \mathrm{s}\right)>\left(V_{\text {Aluminum }}=3295 \mathrm{~m} / \mathrm{s}\right)$ $>\left(V_{\text {Cooper }}=3184 \mathrm{~m} / \mathrm{s}\right)$; the time when the jet began to fracture was $\left(t_{\text {Cooper }}=112.8 \mu \mathrm{s}\right)>\left(t_{\text {Steel }}=104.8 \mu \mathrm{s}\right)$ $>\left(t_{\text {Aluminum }}=90 \mu \mathrm{s}\right)$; the penetration completion time is $\left(T_{\text {Cooper }}=182 \mu \mathrm{s}\right)<\left(T_{\text {Aluminum }}=190 \mu \mathrm{s}\right)$ $<\left(T_{\text {Steel }}=192 \mu \mathrm{s}\right)$.

(2) The experimental results show that the shaped charge warhead with the copper liner can still form a good penetration ability against $25 \mathrm{~mm}$ Q235 steel target after penetrating the simulated cabin and has good after-effect damage ability; that is, the penetration ability of residual jet can penetrate $10 \mathrm{~mm}$ Q235 steel target.

\section{Data Availability}

The data that support the findings of this study are available from the corresponding author upon reasonable request.

\section{Conflicts of Interest}

The authors declare that they have no conflicts of interest.

\section{References}

[1] J. P. Yin and Z. J. Wang, Ammunition, Beijing Institute of Technology Press, Beijing, China, 2005.
[2] F. Y. Lu, X. Y. Li, and Y. L. Lin, Structure and Principle of Warhead, Science Press, Beijing, China, 2009.

[3] W. Xu, C. Wang, and D. Chen, "Formation of a bore-center annular shaped charge and its penetration into steel targets," International Journal of Impact Engineering, vol. 127, pp. 122-134, 2019.

[4] Z. Rosenberg, Y. Ashuach, Y. Yeshurun, and E. Dekel, "On the main mechanisms for defeating AP projectiles, long rods and shaped charge jets," International Journal of Impact Engineering, vol. 36, no. 4, pp. 588-596, 2009.

[5] X. Bai, J. X. Liu, S. K. Li, C. C. Lv, W. Q. Guo, and T. T. Wu, "Effect of interaction mechanism between jet and target on penetration performance of shaped charge liner," Materials Science and Engineering A, vol. 553, pp. 142-148, 2012.

[6] B. X. Ren, G. Tao, P. Wen, C. X. Du, C. Q. Pang, and H. B. Meng, "Analysis of the formation mechanism of the slug and jet center hole of axisymmetric shaped charges," Results in Physics, vol. 9, pp. 135-141, 2018.

[7] S. V. Fedorov, A. V. Babkin, S. V. Ladov, G. A. Shvetsov, and A. D. Matrosov, "Possibilities of controlling the shapedcharge effect by electromagnetic actions," Combustion, Explosion, and Shock Waves, vol. 36, no. 6, pp. 792-808, 2000.

[8] G. A. Shvetsov, A. D. Matrosov, S. V. Fedorov, A. V. Babkin, and S. V. Ladov, "Effect of external magnetic fields on shapedcharge operation," International Journal of Impact Engineering, vol. 38, no. 6, pp. 521-526, 2011.

[9] B. Ma, Z.-X. Huang, X.-D. Zu, and Q.-Q. Xiao, "Experimental study on external strong magnetic fields coupling with the shaped charge jet," International Journal of Impact Engineering, vol. 98, pp. 88-96, 2016.

[10] B. Ma, Z. Huang, Z. Guan, X. Zu, X. Jia, and Q. Xiao, "Research of the axial strong magnetic field applied at the initial period of inertial stretching stage of the shaped charge jet," International Journal of Impact Engineering, vol. 113, pp. 54-60, 2018.

[11] B. Ma, Z. Huang, Z. Guan, X. Jia, Q. Xiao, and X. Zu, "Theoretical analysis of the acceleration effect of the magnetic field on the shaped charge jet," International Journal of Mechanical Sciences, vol. 133, pp. 283-287, 2017.

[12] P. Dehestani, A. R. Fathi, and H. M. Daniali, "Numerical study of the stand-off distance and liner thickness effect on the penetration depth efficiency of shaped charge process," Proceedings of the Institution of Mechanical Engineers, Part C: Journal of Mechanical Engineering Science, vol. 233, no. 3, pp. 977-986, 2018.

[13] R. Li, W. B. Li, X. D. Guo, L. Liang, W. B. Li, and X. M. Wang, "Effect of the annular multi-point initiation control parameters on jet formation," Propellants, Explosives, Pyrotechnics, vol. 44, no. 2, pp. 127-137, 2019. 
[14] Q.-Q. Xiao, Z.-X. Huang, X. Zu, X. Jia, Q.-F. Zhu, and W. Cai, "Shaped charge penetration into high- and ultrahigh-strength Steel-Fiber reactive powder concrete targets," Defence Technology, vol. 16, no. 1, pp. 217-224, 2020.

[15] Q.-F. Zhu, Z.-X. Huang, Q.-Q. Xiao, X.-D. Zu, and X. Jia, "Theoretical and experimental study of shaped charge jet penetration into high and ultra-high strength concrete targets," International Journal of Impact Engineering, vol. 122, pp. 431-438, 2018.

[16] T. Elshenawy, A. Elbeih, and Q. M. Li, "Influence of target strength on the penetration depth of shaped charge jets into RHA targets," International Journal of Mechanical Sciences, vol. 136, pp. 234-242, 2018.

[17] X. Jia, Z.-X. Huang, X.-D. Zu, X.-H. Gu, and Q.-Q. Xiao, "Theoretical analysis of the disturbance of shaped charge jet penetrating a woven fabric rubber composite armor," International Journal of Impact Engineering, vol. 65, pp. 69-78, 2014.

[18] W. L. Xu, C. Wang, and D. P. Chen, "The jet formation and penetration capability of hypervelocity shaped charges," International Journal of Impact Engineering, vol. 132, pp. 1-15, Article ID 103337, 2019.

[19] H. Guo, Y. Zheng, Q. Yu, C. Ge, and H. Wang, "Penetration behavior of reactive liner shaped charge jet impacting thick steel plates," International Journal of Impact Engineering, vol. 126, pp. 76-84, 2019.

[20] H.-G. Guo, Y.-F. Zheng, L. Tang, Q.-B. Yu, C. Ge, and H.-F. Wang, "Effect of wave shaper on reactive materials jet formation and its penetration performance," Defence Technology, vol. 15, no. 4, pp. 495-505, 2019.

[21] H. F. Wang, H. G. Guo, B. Q. Ge, Q. B. Yu, and Y. F. Zheng, "Application of PTFE/Al reactive materials for double-layered liner shaped charge," Materials, vol. 12, no. 17, pp. 1-18, 2019.

[22] L. L. Ding, W. H. Tang, and X. W. Ran, "Simulation study on jet formability and damage characteristics of a low-density material liner," Materials, vol. 11, no. 1, pp. 1-17, 2018.

[23] C. Wang, W. Xu, and S. C. K. Yuen, "Penetration of shaped charge into layered and spaced concrete targets," International Journal of Impact Engineering, vol. 112, pp. 193-206, 2018.

[24] J. B. Men, J. W. Jiang, and S. Y. Wang, Fundamentals of Numerical Simulation for Explosion and Shock Problems, Vol. 7, Beijing Institute of Technology Press, Beijing, China, 2015.

[25] J. Liu, Y. Long, C. Ji, M. Zhong, and Q. Liu, "The influence of liner material on the dynamic response of the finite steel target subjected to high velocity impact by explosively formed projectile," International Journal of Impact Engineering, vol. 109, pp. 264-275, 2017.

[26] D. J. Steinberg, Equation of State and Strength Properties of Selected Materials, Lawrence Livermore National Laboratory, Livermore, CA, USA, 2003.

[27] J. P. Yin, Y. Y. Han, X. F. Wang, B. H. Chang, F. D. Dong, and Y. J. Xu, "A new charge structure based on computer modeling and simulation analysis," Journal of Visual Communication and Image Representation, vol. 64, no. 7, pp. 1-10, 2019. 